\title{
Analysis of the effects of air polishing powders containing sodium bicarbonate and glycine on human teeth
}

\author{
Julia Bühler • Fredy Schmidli • Roland Weiger • \\ Clemens Walter
}

Received: 31 March 2014 / Accepted: 8 September 2014 / Published online: 21 September 2014

(C) Springer-Verlag Berlin Heidelberg 2014

\begin{abstract}
Objectives The aim of this study was an analysis of the root surface roughness caused by air polishing powders containing sodium bicarbonate or glycine.

Methods The roots of human molars were sectioned into dentin discs and irradiated with three different powders: (A) sodium bicarbonate $(\operatorname{dv} 50=62 \mu \mathrm{m})$, (B) glycine $(\operatorname{dv} 50=$ $49 \mu \mathrm{m})$ and $(\mathrm{C})$ glycine $(\operatorname{dv} 50=21 \mu \mathrm{m})$. Standardized conditions in terms of instrumentation time ( 5 and $10 \mathrm{~s}$ ), pressure (1.8 bar), distance $(2$ and $5 \mathrm{~mm})$ and angulation $\left(45^{\circ}\right.$ and $\left.90^{\circ}\right)$ were applied. Surface roughness (DIN EN ISO 4287:1998) of the probes was analysed by means of the surface profile values "Pa" and "Pt" and the surface roughness value "Rz". The effect of treatment (treated vs. untreated) was studied on each disc. Geometric mean ratios (GMRs) from mixed effects models and confidence intervals $(95 \% \mathrm{CI})$ were calculated. Results For $\mathrm{Pa}$, the comparison revealed significant differences between powders A and B (GMR 3.57, $95 \%$ CI 2.87-4.43, $p<0.001$ ) and powders A and C (GMR 2.72, $95 \%$ CI $2.20-3.37, p<0.001)$ for the overall effects. With respect to $\mathrm{Pt}$, significant differences occurred between powders A and B (GMR 2.49, $95 \%$ CI 2.11-2.94, $p<0.001$ ) and powders A and C (GMR 2.39, $95 \%$ CI 2.03-2.82, $p<0.001$ ). Between powders $\mathrm{B}$ and $\mathrm{C}$, there were no significant differences for $\mathrm{Pa}, \mathrm{Rz}$ and $\mathrm{Pt}$.

Conclusion Air polishing powders containing glycine caused significantly less alterations on human root surfaces compared to powders containing sodium bicarbonate.
\end{abstract}

J. Bühler $\cdot$ R. Weiger $\cdot$ C. Walter $(\bowtie)$

Department of Periodontology, Endodontology and Cariology,

University of Basel, Hebelstrasse 3, 4056 Basel, Switzerland

e-mail: clemens.walter@unibas.ch

F. Schmidli

Institute for Materials Science, Technology and Propaedeutics,

University of Basel, Hebelstrasse 3, Basel 4056, Switzerland
Clinical significance Powders containing glycine caused a significantly lower increase in root surface roughness compared to those containing sodium bicarbonate. Powders containing sodium bicarbonate may not be indicated for root surface treatment.

Keywords Periodontal therapy $\cdot$ Human teeth $\cdot$ Subgingival instrumentation - Air polishing - Surface roughness ·

Supportive periodontal treatment

\section{Introduction}

To maintain a balance between the ongoing microbiological attack and the ever-changing immune response of the affected host is one of the major objectives of supportive periodontal therapy (SPT). Doing so, a reoccurrence or onset of periodontal and other oral diseases and tooth loss is targeted for treatment [1]. While there is often a need to remove hard deposits from the root surface during initial scaling and root planing, the deterioration of the subgingival biofilm is the primary focus of subgingival instrumentation in SPT. Besides the debate on the correct calculation of the individual frequency of SPT, there is strong evidence for the importance of regular SPT in maintaining periodontal health, particularly in the long term and for patients with an increased risk for progression and/or reoccurrence of periodontitis [2-6]. Several instruments and techniques, including hand instruments and ultrasonic devices, are available for non-surgical debridement during SPT $[7,8]$. As a result of such treatment, adverse effects, including gingival recession and dentin hypersensitivity, may however occur [9-11]. In addition, the regular instrumentation of the root surface may also contribute to a removal of root substance due to the high abrasiveness of certain instruments or air polishing powders [12-15]. In the past few years, periodontal research focused on alternatives 
for instrumentation during SPT [16-18]. In 2003, air polishing powders containing glycine were introduced for SPT [19]. They show promising results in vitro and clinically. Less abrasiveness of early introduced powders containing glycine compared to those containing sodium bicarbonate or calcium carbonate was reported [15, 20-22]. Clinical results in particular highlight consistently the minor discomfort compared to conventional instrumentation using curettes or ultrasonic devices [18, 23-25]. However, to what extent these powders may modify human tooth surfaces or increase surface roughness has not been sufficiently documented. A quantification of surface modifications with validated examination methods (i.e. measuring profile and surface roughness) is lacking [26, 27]. The aim of this study was an analysis of the root surface roughness of human teeth after air polishing with powders containing glycine or sodium bicarbonate.

\section{Material and methods}

\section{Preparation of dentin discs}

The study protocol was approved by the Ethics Committee of Basel (Ref. Nr. EK:135/10). One hundred twenty anonymised caries-free extracted maxillary and mandibular third, second and first molars stored in a solution of water mixed with chlorhexidine $(0.1 \%)$ were obtained from the tooth bank at the school of dental medicine of the University of Basel. Only teeth with unaltered root surfaces, i.e. no caries or calculus and no signs of previous periodontal instrumentation or damage due to extraction, were used. The root surfaces were sectioned into square dentin discs of approximately $2 \times 2 \mathrm{~mm}$ and a thickness of $1 \mathrm{~mm}$ and stored in $4{ }^{\circ} \mathrm{C}$ saline solution for no longer than 30 days. The discs were glued on aluminium stubs (Stiftprobenteller, Plano GmbH, Wetzlar, Germany) with a cold curing adhesive (DELO-AUTOMIX 1895 2K-Epoxy, DELO, Landsberg, Germany). The discs were instrumented using Gracey curettes (Deppeler, Rolle, Switzerland) with overlapping strokes, i.e. 10 strokes in one direction followed by 10 strokes in the opposite direction. The effect of instrumentation was analysed with magnifying glasses $(\times 2.5$ magnification). One half of the disc served as untreated control and was protected with a circumferential secured silicone layer (AFFINIS light body, Coltène Whaledent, Altstätten, Switzerland). Dentin discs were randomly assigned into 24 different treatment groups.

Application of air polishing powders

The effects of three different powders on human root surfaces were analysed. Numerical values of particle sizes of the powders used are given in volume. The symbol "dv" describes the particle size distribution ("d"= diameter, "v"=volume), i.e. $(\operatorname{dv} 50)=50 \%$ of the particle's volume is smaller than this value and $50 \%$ is bigger. The following grain sizes of the powders were provided by the manufacturer:

(A) Sodium bicarbonate (AIR-FLOW CLASSIC, EMS SA, Nyon, Switzerland), grain size distribution: dv50 $=62 \mu \mathrm{m}$, $\mathrm{dv} 90=150 \mu \mathrm{m}$

(B) Glycine (AIR-FLOW SOFT, EMS SA, Nyon, Switzerland), grain size distribution: $\operatorname{dv} 50=49 \mu \mathrm{m}$, $\operatorname{dv} 90=146 \mu \mathrm{m}$

(C) Glycine (AIR-FLOW PERIO, EMS SA, Nyon, Switzerland), grain size distribution: $\operatorname{dv} 50=21 \mu \mathrm{m}$, $\operatorname{dv} 90=51 \mu \mathrm{m}$

An air polishing device (AIR-FLOW Master, EMS SA, Nyon, Switzerland, standard handpiece) was installed in an automated apparatus to accomplish instrumentation under defined and standardized conditions. Powder and water settings were standardized to $50 \%$ of the maximum level. A dynamic pressure of 1.8 bar was used. The air polishing powders were applied using different exposure times $(5 \mathrm{~s}$, $10 \mathrm{~s})$, distances $(2 \mathrm{~mm}, 5 \mathrm{~mm})$ and angulations $\left(45^{\circ}, 90^{\circ}\right)$. Every setting was carried out five times. In order to document the powder emission [28], the powder chamber was weighted using a precision balance (PG503-S DeltaRange, Mettler Toledo, Greifensee, Switzerland) before and after instrumentation of each disc.

\section{Analysis of surface modifications}

Immediately after exposure to the air polishing powder, the discs were cleaned with a water spray for $10 \mathrm{~s}$ and then dried with an air spray. The surface modifications after instrumentation were quantified using software-based roughness measurements (Tactile Stylus Hommel Tester T1000, cantilever Typ TKK 50, Hommel \& Seitz, Germany) and related to the untreated sides of the discs. Every side of the disc (treated and untreated) was scanned three times over a distance of $1.5 \mathrm{~mm}$ each.

Three defined parameters of surface roughness were analysed: the Pa value (i.e. the arithmetical mean deviation) is defined as the arithmetic average of the unfiltered raw profile (DIN EN ISO 4287, Berlin, Germany) [27], the Pt value (i.e. the average maximum height of the profile) is defined as the sum of the largest profile peak height and the largest profile valley within an evaluation length (DIN EN ISO 4287, Berlin, Germany) [27] and the Rz value (i.e. the maximum height of the roughness profile) is defined as the sum from the height of the highest profile peak and the depth of the lowest profile valley within a sampling length (DIN EN ISO 4287, Berlin, Germany) [27]. As Pa and Pt are surface profile values, they can paraphrase the depth of a surface 
defect, whereas Rz is a surface roughness value and circumscribes the roughness of a surface.

\section{Scanning electron microscopy}

Three-dimensional scanning electron microscopy (SEM) images were calculated to illustrate surface modifications. The discs were sputter coated with gold of a layer thickness of $15 \mathrm{~nm}$ (Bal-Tec SCD 005 Sputter Coating Unit, Tucson, USA) for $120 \mathrm{~s}$ with a current of $25 \mathrm{~mA}$ and observed in a high-resolution SEM (Philips XL30 ESEM, Eindhoven, Netherlands) at an accelerating voltage of $10 \mathrm{kV}$ with a eucentric sample stage. Three pictures were made of the same spot but in three different sample angles $\left(+10^{\circ}, 0^{\circ},-10^{\circ}\right)$ at a sample spacing of $10 \mathrm{~mm}$. Image processing was made with 3D reconstruction of SEM images (MeX 5.0 Alicona $\mathrm{MeX}$, Alicona Imaging GmbH, Graz, Austria).

\section{Statistical analysis}

Descriptive statistics of the raw data for the treated and untreated surfaces were expressed as mean $\pm \operatorname{SEM}$ (standard error of the mean).

"Pa", "Rz" and "Pt" are log-normal distributed; hence, all comparisons have to be expressed as geometric mean ratios (GMRs). Comparisons within $\mathrm{Pa}$ and $\mathrm{Rz}$ were expressed as geometric mean ratios subtracted to the mean of the untreated control. However, comparisons within $\mathrm{Pt}$ were expressed as geometric mean ratios subtracted to the maximal difference to the untreated control. In order to compare the powders, linear mixed effects models were performed. Dependent variables were $\mathrm{Pa}, \mathrm{Rz}$ and $\mathrm{Pt}$, and independent variables were "powders", "distance", "time" and "angulation". "Tooth" is treated as a random factor. The interaction between powders, distance, time and angulation was also included in the regression models. The interaction tests a possible changing dependence of distance, time and angulation across powders. Additionally, overall effects of "methods", distance, time and angulation were also calculated. Results are expressed as geometric mean ratios \pm 2 SEM ( 2 standard error of the mean) with $95 \%$ confidence intervals and $p$ values. All comparisons were adjusted for multiple comparisons using Tukey's method [29]. Descriptive statistics cannot be directly compared to the estimated GMRs because GMRs are calculated based on ratios of subtracted baseline means, but the means and SEMs are based on raw data.

A $p$ value $<0.05$ is considered as significant. All analyses were done using $\mathrm{R}$ version 2.15.1 [30]. The statistical analysis was performed by Andreas Schötzau, Basel, Switzerland.

\section{Results}

One hundred twenty teeth were randomly assigned to the treatment groups. The mean Vickers hardness of the pretreated teeth was assessed (ZHU ZwickiLine 0.2/Z2.5, Zwick GmbH \& Co. KG, Ulm, Germany) on randomly selected teeth $(n=30)$ and was $61.0 \pm 10.9$ with a load of $0.5 \mathrm{~N}$ (hardness from reference HV=65.6 \pm 3.9 [31]). The mean powder emission rate and its standard deviation were $0.29 \pm$ $0.11 \mathrm{~g}$ for powder $\mathrm{A}, 0.27 \pm 0.17 \mathrm{~g}$ for powder $\mathrm{B}$ and $0.48 \pm$ $0.15 \mathrm{~g}$ for powder $\mathrm{C}$. Three roughness parameters were analysed. The results are shown in Figs. 1, 2, 3 and 4.

\section{$\mathrm{Pa}$}

The raw data for the treated and untreated surfaces and the results of the linear mixed effects models analysis represented as GMR are shown in Fig. 1a-d for the Pa values. There were significant differences $(p<0.05)$ for the overall effects on $\mathrm{Pa}$ between the treated and the untreated part of the discs for powders A (GMR 6.79, $95 \%$ CI $4.43-10.38, p<0.001$ ), B (GMR 1.90, $95 \%$ CI 1.23-2.95, $p=0.004$ ) and C (GMR 2.49, $95 \%$ CI $1.63-3.82, p<0.001)$. Significant differences occurred for the comparison of the effects caused by powders A vs. B (GMR 3.57, $95 \%$ CI 2.87-4.43, $p<0.001)$ and A vs. C (GMR 2.72, $95 \%$ CI 2.20-3.37, $p<0.001$ ). The differences of the Pa caused by powders $\mathrm{B}$ and $\mathrm{C}$ were not statistically significant (GMR 0.76, $95 \%$ CI 0.62-0.95, $p=0.423$ ).

Significant interactions occurred between powders and time $(p=0.004)$ and powders and angulation $(p=0.020)$. Other interactions of interest were not significant. This indicates that the influence of powders on Pa depends on time and angulation but not on distance. Hence, the influence of distance is similar for all powders. Therefore, the geometric mean ratios of $\mathrm{Pa}$ were demonstrated for each time and angulation (Fig. 1a-d). The comparison between powders A and B revealed significant differences in GMR with more pronounced effects caused by powder A for the three combinations $45^{\circ} / 5 \mathrm{~s}(p=0.028), 45^{\circ} / 10 \mathrm{~s}(p<0.001)$ and $90^{\circ} / 10 \mathrm{~s}(p=$ $0.006)$. With respect to GMR differences between powders A and $\mathrm{C}$, significant differences occurred for a treatment time of $10 \mathrm{~s}$ and an angulation of $45^{\circ}(p<0.001)$. There were no significant differences between the GMR for powders B and $\mathrm{C}$ at both angulations or exposure times.

$\mathrm{Pt}$

The raw data for the treated and untreated surfaces and the results of the linear mixed effects models analysis represented as GMR are shown in Fig. 2a-d for the Pt values. Significant differences for the overall effects on Pt occurred between the treated and untreated sides of the discs for powder A (GMR 7.05, $95 \%$ CI 5.07-9.78, $p<0.001$ ), powder B (GMR 2.83, 


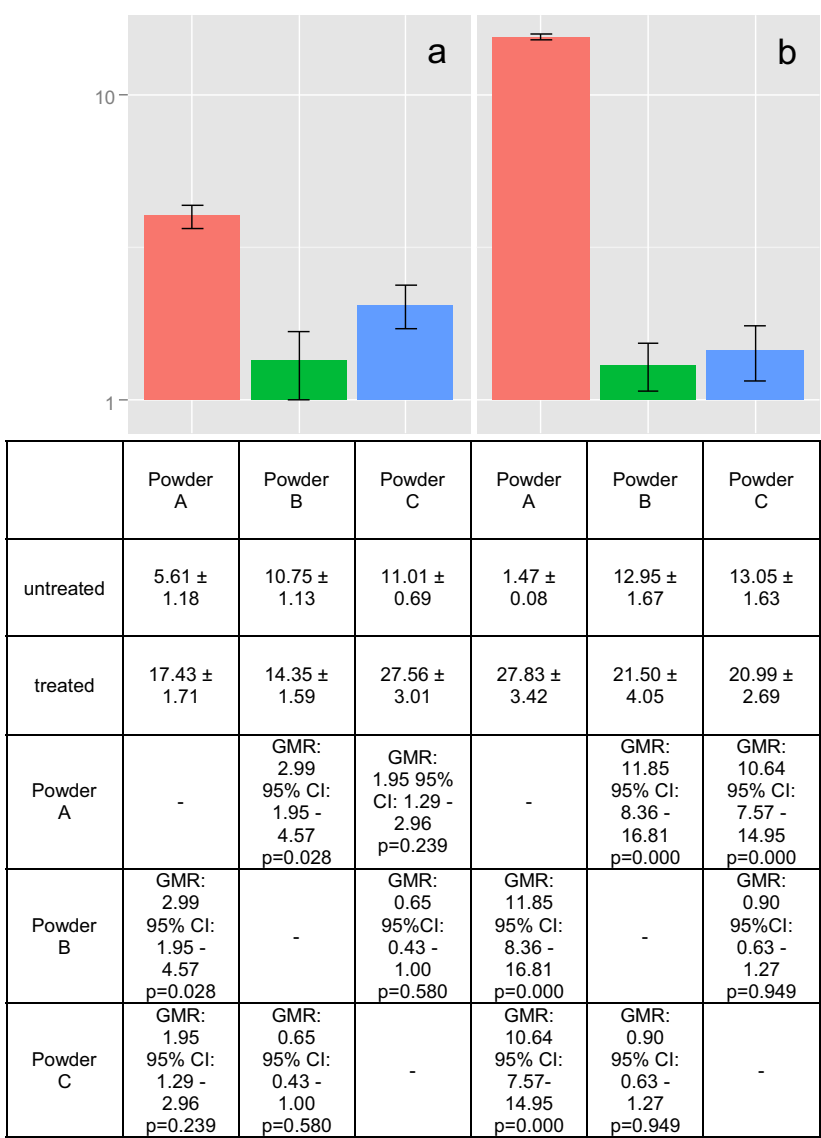

Fig. 1 Surface profile value $\mathrm{Pa}$ analysis. The raw data $(\mu \mathrm{m})$ for the treated and untreated surfaces are shown in the first two lines of the table. Bars represent the results of the linear mixed effects models analysis represented as geometric mean ratio $(G M R)$ of $\mathrm{Pa}$ subtracted to the mean

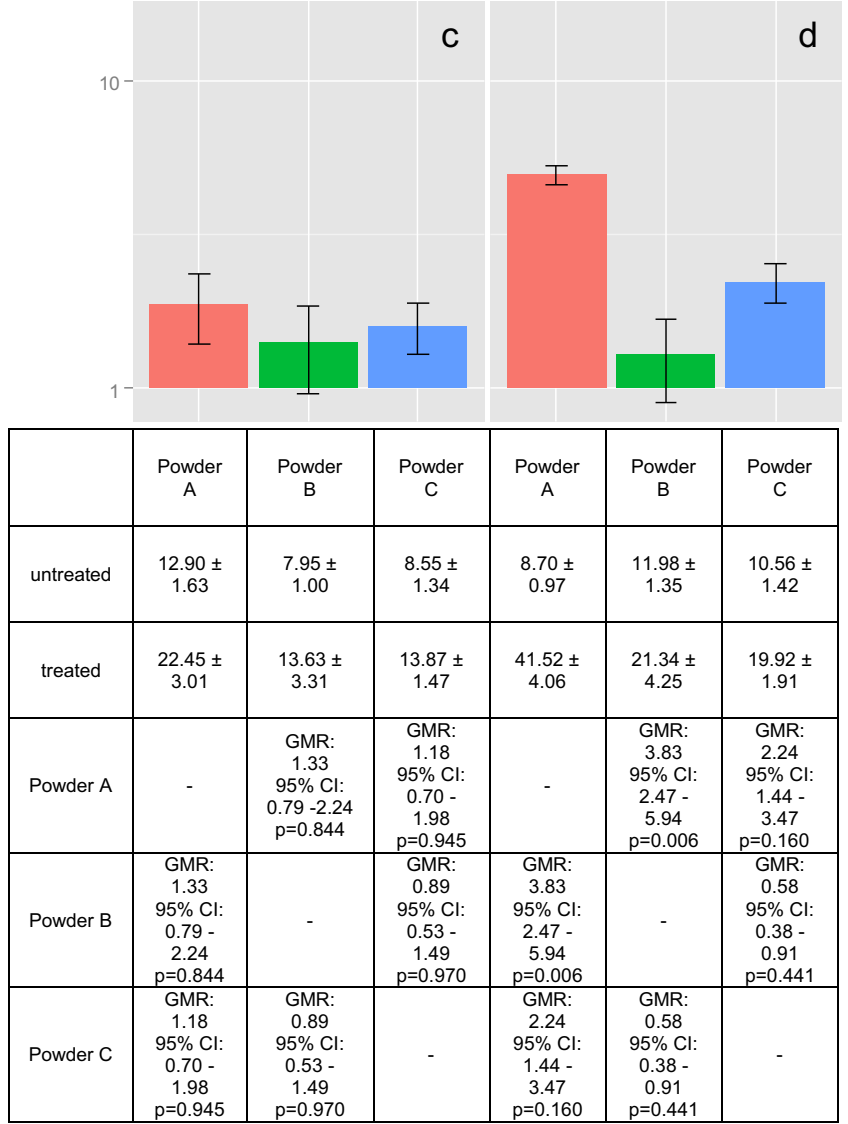

of the untreated surfaces $( \pm 2 \mathrm{SEM})$ for the following combinations of parameters: angulation of $45^{\circ}: \mathbf{a}$ exposure time of $5 \mathrm{~s}, \mathbf{b}$ exposure time of $10 \mathrm{~s}$, and angulation of $90^{\circ}: \mathbf{c}$ exposure time of $5 \mathrm{~s}, \mathbf{d}$ exposure time of $10 \mathrm{~s}$

$\mathrm{Rz}$

The raw data for the treated and untreated surfaces and the results of the linear mixed effects models analysis represented as GMR are shown in Fig. 3a, b for the Rz values. There were significant differences $(p<0.005)$ for the overall effects between the treated and the untreated part of the discs for powders A (GMR 1.68, $95 \%$ CI 1.36-2.08, $p<0.001$ ), B (GMR 1.42, $95 \%$ CI 1.14-1.77, $p=0.002$ ) and C (GMR $1.49,95 \%$ CI 1.21-1.84, $p<0.001)$. The comparison between the powders revealed GMR $1.19,95 \%$ CI $1.07-1.32, p=$ 0.251 for A vs. B, GMR 1.13, $95 \%$ CI 1.02-1.26, $p=0.478$ for A vs. C and GMR 0.95, $95 \%$ CI 0.86-1.06, $p=0.897$ for B vs. C.

There were significant interactions between powders and distance $(p=0.018)$. This indicates that the influence of powders on Rz depends on distance but not on time and angulation. Hence, the influence of time and angulation is similar for all powders. Other interactions of interest were not significant. Therefore, powders were compared for each distance separately. The comparison between powders A and $\mathrm{B}(p=0.029)$ and powders $\mathrm{A}$ and $\mathrm{C}(p=0.013)$ revealed significant 


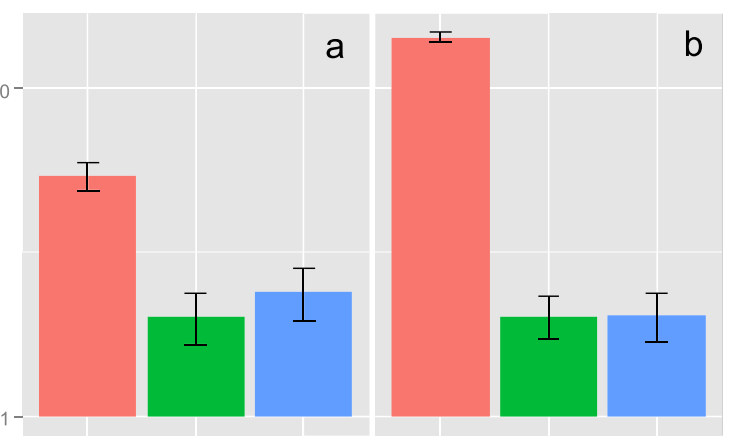

\begin{tabular}{|c|c|c|c|c|c|c|}
\hline & $\begin{array}{l}\text { Powder } \\
\text { A }\end{array}$ & $\begin{array}{c}\text { Powder } \\
\text { B }\end{array}$ & $\begin{array}{l}\text { Powder } \\
\text { C }\end{array}$ & $\begin{array}{c}\text { Powder } \\
\text { A }\end{array}$ & $\begin{array}{l}\text { Powder } \\
\text { B }\end{array}$ & $\begin{array}{l}\text { Powder } \\
\text { C }\end{array}$ \\
\hline untreated & $\begin{array}{c}32.52 \pm \\
6.49\end{array}$ & $\begin{array}{c}59.27 \pm \\
5.49\end{array}$ & $\begin{array}{c}63.93 \pm \\
3.32\end{array}$ & $\begin{array}{c}10.50 \pm \\
0.67\end{array}$ & $\begin{array}{c}64.85 \pm \\
7.54\end{array}$ & $\begin{array}{c}67.77 \pm \\
7.86\end{array}$ \\
\hline treated & $\begin{array}{c}81.62 \pm \\
7.53\end{array}$ & $\begin{array}{c}76.04 \pm \\
7.80\end{array}$ & $\begin{array}{c}130.13 \pm \\
12.97\end{array}$ & $\begin{array}{c}121.75 \pm \\
15.29\end{array}$ & $\begin{array}{c}99.50 \pm \\
13.60\end{array}$ & $\begin{array}{c}100.15 \pm \\
11.24\end{array}$ \\
\hline $\begin{array}{l}\text { Powder } \\
\text { A }\end{array}$ & - & $\begin{array}{c}\text { GMR: } \\
2.68 \\
95 \% \mathrm{Cl}: \\
1.95- \\
3.69 \\
\mathrm{p}=0.006 \\
\end{array}$ & $\begin{array}{c}\text { GMR: } \\
2.26 \\
95 \% \mathrm{Cl}: \\
1.66- \\
3.09 \\
\mathrm{p}=0.024 \\
\end{array}$ & - & $\begin{array}{c}\text { GMR: } \\
7.10 \\
95 \% \mathrm{Cl}: \\
5.42- \\
9.30 \\
\mathrm{p}=0.000\end{array}$ & $\begin{array}{c}\text { GMR: } \\
7.06 \\
95 \% \mathrm{Cl}: \\
5.39- \\
9.25 \\
\mathrm{p}=0.000\end{array}$ \\
\hline $\begin{array}{l}\text { Powder } \\
\text { B }\end{array}$ & $\begin{array}{c}\text { GMR: } \\
2.68 \\
95 \% \mathrm{Cl}: \\
1.95- \\
3.69 \\
\mathrm{p}=0.006 \\
\end{array}$ & - & $\begin{array}{c}\text { GMR: } \\
0.84 \\
95 \% \mathrm{Cl}: \\
0.61- \\
1.16 \\
\mathrm{p}=0.857\end{array}$ & $\begin{array}{c}\text { GMR: } \\
7.10 \\
95 \% \mathrm{Cl}: \\
5.42- \\
9.30 \\
\mathrm{p}=0.000\end{array}$ & - & $\begin{array}{c}\text { GMR: } \\
1.00 \\
95 \% \mathrm{Cl}: \\
0.76- \\
1.30 \\
\mathrm{p}=1.000\end{array}$ \\
\hline $\begin{array}{l}\text { Powder } \\
\text { C }\end{array}$ & $\begin{array}{c}\text { GMR: } \\
2.26 \\
95 \% \mathrm{Cl} \\
1.66- \\
3.09 \\
\mathrm{p}=0.024\end{array}$ & $\begin{array}{c}\text { GMR: } \\
0.84 \\
95 \% \mathrm{Cl}: \\
0.61- \\
1.16 \\
\mathrm{p}=0.857\end{array}$ & 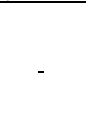 & $\begin{array}{c}\text { GMR: } \\
7.06 \\
95 \% \mathrm{Cl}: \\
5.39- \\
9.25 \\
\mathrm{p}=0.000\end{array}$ & $\begin{array}{c}\text { GMR: } \\
1.00 \\
95 \% \mathrm{Cl}: \\
0.76- \\
1.30 \\
\mathrm{p}=1.000\end{array}$ & - \\
\hline
\end{tabular}

Fig. 2 Surface profile value Pt analysis. The raw data $(\mu \mathrm{m})$ for the treated and untreated surfaces are shown in the first two lines of the table. Bars represent the results of the linear mixed effects models analysis represented as geometric mean ratio $(G M R)$ of Pt subtracted to the mean of the

differences in GMR with more pronounced effects caused by powder $\mathrm{A}$ for the distance of $2 \mathrm{~mm}$. There were no significant differences between the GMR for powders B and C $(p>0.05)$ at both distances.

\section{Discussion}

The results of this in vitro study demonstrate significant differences in terms of three surface roughness parameters, i.e. $\mathrm{Pa}, \mathrm{Pt}$ and $\mathrm{Rz}$, between air polishing powders containing sodium bicarbonate and glycine of different grain sizes.

All powders were compared to each other and all caused alterations of the root surface in vitro. However, significantly less pronounced effects occurred after treatment with glycine on root surfaces of human teeth compared to the powder consisting of sodium bicarbonate. The glycine powders varied in terms of grain size distribution. The differences with regard to the parameters analysed between the two tested glycine

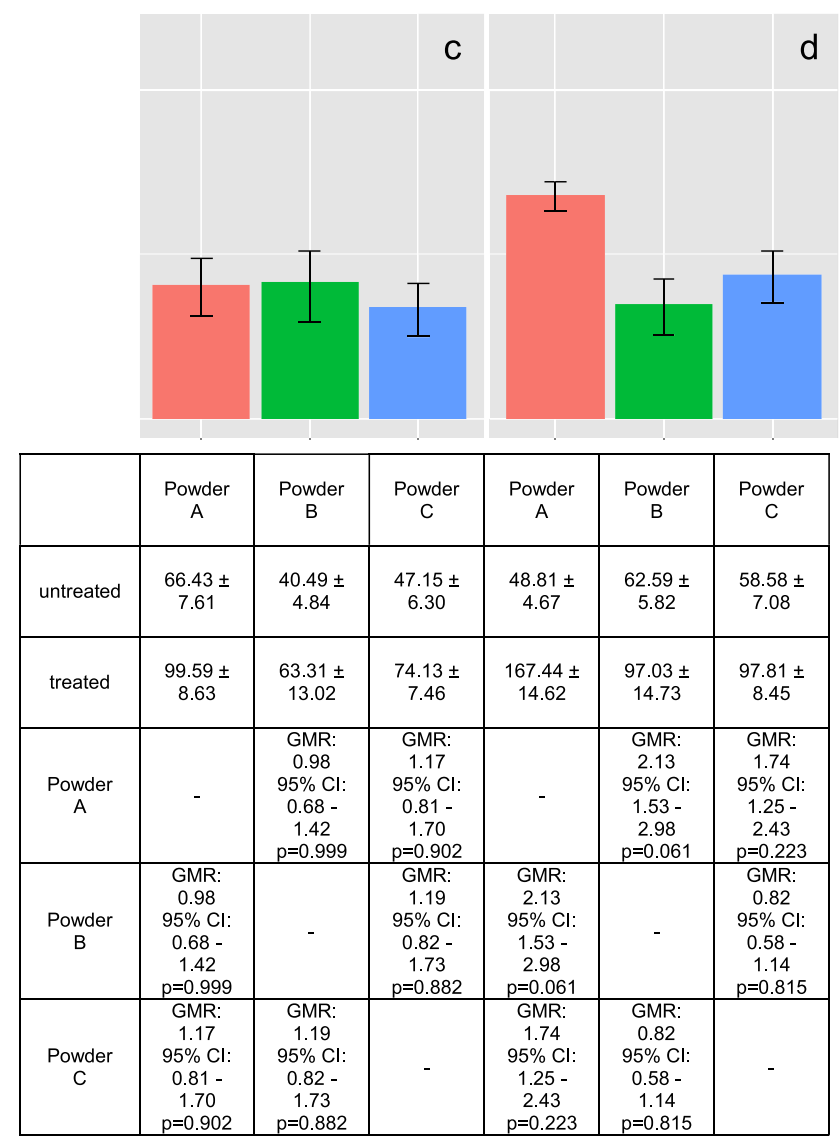

untreated surfaces $( \pm 2 \mathrm{SEM})$ for the following combinations of parameters: angulation of $45^{\circ}:$ a exposure time of $5 \mathrm{~s}, \mathbf{b}$ exposure time of $10 \mathrm{~s}$, and angulation of $90^{\circ}$ : $\mathbf{c}$ exposure time of $5 \mathrm{~s}, \mathbf{d}$ exposure time of $10 \mathrm{~s}$

powders were negligible. Therefore, the powders may have similar effects on human root surfaces. As roughness and not substance loss has been assessed in the present study, inference on the abrasiveness of the assessed powders is not possible by implication. It may be that one instrumentation method results in a rougher surface but does remove less overall root substance than another method that leaves behind a smoother surface. However, the effects on periodontal soft tissues are also relevant and may be affected by the grain size of the powder. A study analysing human gingival biopsies after treatment with a glycine powder $(\operatorname{dv} 90=63 \mu \mathrm{m})$ showed significantly less gingival erosions compared to instrumentation with curettes or sodium bicarbonate [32]. Although the powder used in that particular study is from a different manufacturer, the data might be comparable to some extent with powder $\mathrm{C}(\mathrm{dv} 90=51 \mu \mathrm{m})$ used in this study. The distinct effects of powders $\mathrm{B}$ and $\mathrm{C}$ on human gingiva are unknown and remain open for further research. In addition, powder $\mathrm{C}$ was evaluated clinically with respect to patient perception. The results of these clinical studies reveal that a treatment with this powder was perceived as significantly more pleasant 
a

\begin{tabular}{|c|c|c|c|c|c|c|}
\hline & $\begin{array}{c}\text { Powder } \\
\text { A }\end{array}$ & $\begin{array}{c}\text { Powder } \\
\text { B }\end{array}$ & $\begin{array}{c}\text { Powder } \\
\text { C }\end{array}$ & $\begin{array}{c}\text { Powder } \\
\text { A }\end{array}$ & $\begin{array}{c}\text { Powder } \\
\text { B }\end{array}$ & $\begin{array}{c}\text { Powder } \\
\text { C }\end{array}$ \\
\hline untreated & $\begin{array}{c}4.07 \pm \\
0.21\end{array}$ & $\begin{array}{c}3.90 \pm \\
0.30\end{array}$ & $\begin{array}{c}4.93 \pm \\
0.29\end{array}$ & $\begin{array}{c}4.17 \pm \\
0.26\end{array}$ & $\begin{array}{c}4.65 \pm \\
0.32\end{array}$ & $\begin{array}{c}3.93 \pm \\
0.21\end{array}$ \\
\hline treated & $\begin{array}{c}9.47 \pm \\
0.58\end{array}$ & $\begin{array}{c}6.21 \pm \\
0.46\end{array}$ & $\begin{array}{c}7.32 \pm \\
0.43\end{array}$ & $\begin{array}{c}5.25 \pm \\
0.28\end{array}$ & $\begin{array}{c}6.10 \pm \\
0.38\end{array}$ & $\begin{array}{c}5.93 \pm \\
0.35\end{array}$ \\
\hline Powder A & - & $\begin{array}{c}\text { GMR: } \\
1.46 \\
95 \% \mathrm{Cl}: \\
1.26- \\
1.70 \\
\mathrm{p}=0.029\end{array}$ & $\begin{array}{c}\text { GMR: } \\
1.51 \\
95 \% \mathrm{Cl}: \\
1.30- \\
1.74 \\
\mathrm{p}=0.013\end{array}$ & - & $\begin{array}{c}\text { GMR: } \\
0.97 \\
95 \% \mathrm{Cl}: \\
0.83- \\
1.12 \\
\mathrm{p}=0.967\end{array}$ & $\begin{array}{c}\text { GMR: } \\
0.85 \\
95 \% \mathrm{Cl}: \\
0.73- \\
0.98 \\
p=0.497\end{array}$ \\
\hline Powder B & $\begin{array}{c}\text { GMR: } \\
1.46 \\
95 \% \mathrm{Cl}: \\
1.26- \\
1.70 \\
\mathrm{p}=0.029\end{array}$ & - & $\begin{array}{c}\text { GMR: } \\
1.03 \\
95 \% \mathrm{Cl}: \\
0.89- \\
1.20 \\
\mathrm{p}=0.979\end{array}$ & $\begin{array}{c}\text { GMR: } \\
0.97 \\
95 \% \mathrm{Cl}: \\
0.83- \\
1.12 \\
\mathrm{p}=0.967\end{array}$ & - & $\begin{array}{c}\text { GMR: } \\
0.88 \\
95 \% \mathrm{Cl}: \\
0.76- \\
1.02 \\
\mathrm{p}=0.652\end{array}$ \\
\hline Powder C & $\begin{array}{c}\text { GMR: } \\
1.51 \\
95 \% \mathrm{Cl}: \\
1.30- \\
1.74 \\
\mathrm{p}=0.013\end{array}$ & $\begin{array}{c}\text { GMR: } \\
1.03 \\
95 \% \mathrm{Cl}: \\
0.89- \\
1.20 \\
\mathrm{p}=0.979\end{array}$ & - & $\begin{array}{c}\text { GMR: } \\
0.85 \\
95 \% \mathrm{Cl}: \\
0.73- \\
0.98 \\
\mathrm{p}=0.497\end{array}$ & $\begin{array}{c}\text { GMR: } \\
0.88 \\
95 \% \mathrm{Cl}: \\
0.76- \\
1.02 \\
\mathrm{p}=0.652\end{array}$ & - \\
\hline
\end{tabular}

Fig. 3 Surface profile value $\mathrm{Rz}$ analysis. The raw data $(\mu \mathrm{m})$ for the treated and untreated surfaces are shown in the first two lines of the table. Bars represent the results of the linear mixed effects models analysis represented as geometric mean ratio $(G M R)$ of $\mathrm{Rz}$ subtracted to the mean of the untreated surfaces $( \pm 2 \mathrm{SEM})$ for the following combinations of parameters: a distance of $2 \mathrm{~mm}$ and $\mathbf{b}$ distance of $5 \mathrm{~mm}$

compared to hand instruments and/or ultrasonics [23, 24]. Such data are currently not available for powder B.

There is an ongoing scientific controversy regarding the aim of the instrumentation of the root surface [26, 33]. Histological evidence demonstrates cellular attachment between junctional epithelium and dental calculus [34]. Historically, a smooth, hard and decontaminated root surface is requested by several authors in order to prevent the documented enhanced bacterial adhesion on rough surfaces [13, 34-36]. However, a consensus regarding the requested roughness/smoothness after instrumentation in terms of physical surface roughness values is lacking to the best of our knowledge. Several hand instruments with different modified tips including Gracey curettes and ultrasonic scalers were developed for instrumentation of the root surface during non-surgical or even surgical treatment $[35,37,38]$. The periodontal scaling procedure causes some undesirable side effects $[10,12]$, leading to efforts for reducing the invasiveness of non-surgical periodontal treatment [39, 40]. Scaling and root planing of the root surface for many years during SPT leads to surface roughness alterations and removal of tooth substance [12, 13, 34], and teeth may develop hypersensitivity or a risk of fracture $[10,11,41]$.

This study was designed for analysis of the surface roughness of human teeth after application of three air polishing powders. In order to be as close as possible to the clinical situation and to provide reasons for a translation to dental practice, several efforts were taken:

1. Sufficient evidence shows differences in terms of chemical, physical and morphological properties between human teeth and teeth from other mammalians [42]. Therefore, only human molar teeth were used for the experiments. The teeth were stored in a solution of water mixed with chlorhexidine $(0.1 \%)$ [21]. The matter of storage medium is widely discussed in the literature and several solutions, including chlorhexidine, chloramine, artificial saliva, saline and thymol, for storage were suggested [14, 15, 20-22, 43]. The storage of extracted human teeth for in vitro studies needs to be kept in mind, since it might affect the physical properties of teeth [44-46]. However, no scientifically accepted consensus regarding the best storage medium is available currently. The effect was taken into account in terms of an analysis of Vickers hardness of a subsample of teeth analysed in this research. The results show a Vickers hardness range very similar to recent studies [31]. In addition, the biological variance of physiological properties of human teeth was considered by the amount of teeth used in this study and the presentation of data using $95 \%$ confidence intervals.

2. The root surface was scaled with the aid of Gracey curettes in order to simulate a root surface after non-surgical periodontal treatment using standard procedures. No grinding of the tooth discs with manufactured devices was performed to create a flat facing. Unevenness and roughness of the tooth surface represent biological variance and occur before and after treatment. Powders applied on a standardized surface may bias the effects caused by distinct powders [20,21].

3. The powders analysed were specially designed for the device used in the study, and the powder emission rate was recorded. In order to provide a controlled emission of the powders, the powder chamber was filled to the maximum level before every treatment of a tooth disc [28]. Data from this analysis showed that the powder emission for the three powders included in this study was predictable. However, an unpredictable powder emission was detected for powders that were not intended for the device according to the manufacturer. Preliminary data on a fourth powder (Sylc Prophy Therapy, OSspray Ltd., 
REM, 5 s
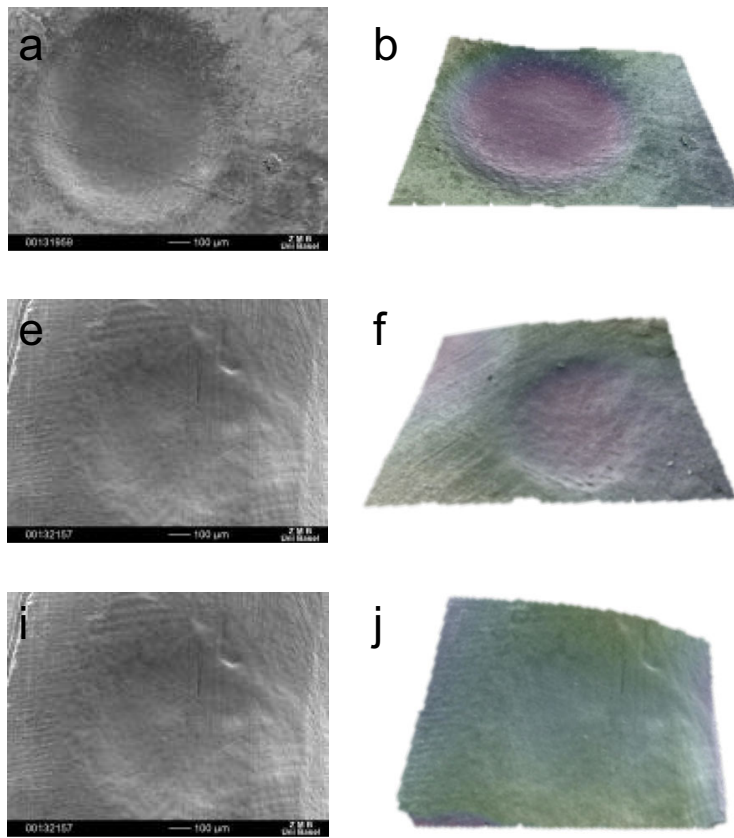

Fig. 4 a-l Representative SEM images of the surface modifications. The modifications of the root surfaces of human teeth after treatment with air polishing powders containing sodium

London, UK) were therefore excluded after the value and mode of powder emission were taken into account [47]. In addition, the parameters powder and water were set to a medium level and the air pressure was held constant.

4. For the registration of surface alterations after air polishing, different validated surface roughness parameters were analysed [27]. The parameters $\mathrm{Pa}, \mathrm{Pt}$ and $\mathrm{Rz}$ are ISO standardized and are commonly used in the field of surface physics to determine the quantitative characterization of surface deviations. The data of this analysis are therefore comparable according to this standard [26, 27]. In addition, three-dimensional scanning electron microscopy was performed for the visualization of the defects (Fig. 4a-1). The images from the latter aspect are in line with data generated using 3D measuring microscopy and micro-computed tomography $[21,48]$. As the surface profile values $\mathrm{Pa}$ and $\mathrm{Pt}$ depict the depth or the maximal defect depth of a surface defect over a defined distance, the standardized surface roughness analysis from this in vitro study may be comparable to some extent with investigations using defect depth and defect volume measurements [14, 15, 20, 21, 27, 48].

In this in vitro study comparing the effects of sodium bicarbonate and glycine powders on the root surface, the powders were delivered with the standard handpiece, i.e. a nozzle designed for supragingival application or for intrasulcular spraying up to 4-mm probing depth [25].
REM, 10s

3D, 10s
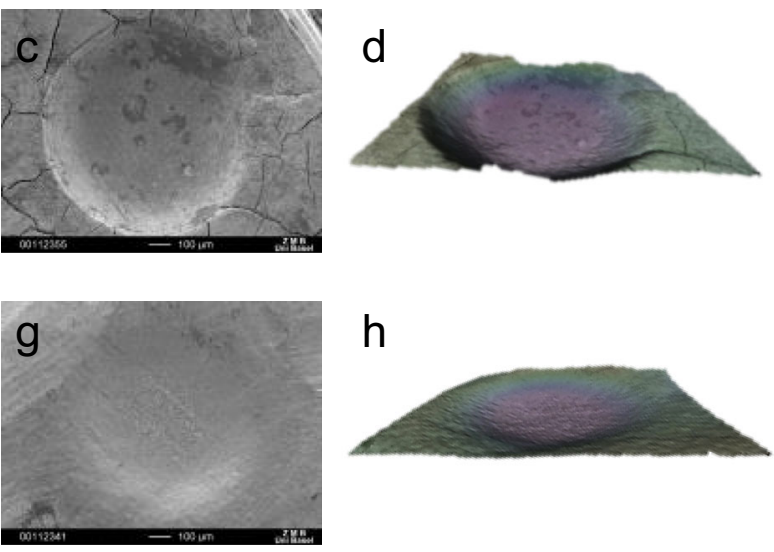

$\mathrm{h}$
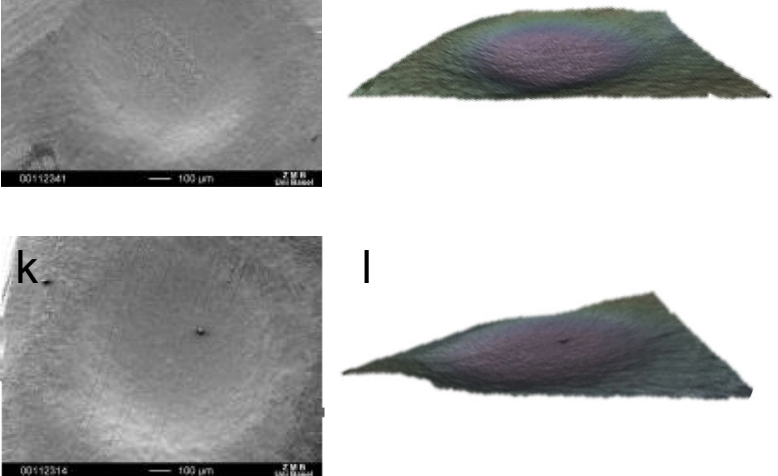

bicarbonate or two different powders containing glycine were analysed using SEM, and three-dimensional images were calculated. Distance of $2 \mathrm{~mm}$, angulation of $90^{\circ}$

Recently, a nozzle for subgingival application was introduced to the market and evaluated clinically $[23,24]$. The different delivery methods may differ in terms of root surface defects, and the results of this study may therefore be applied to the standard handpiece only.

The clinical situation differs from this in vitro analysis. A clinical or ex vivo analysis is challenging and may be limited due to ethical reasons. In the clinical use of air polishing, the distance and angulation of the nozzle as well as the treatment time are not constant and may vary among the different surfaces of the different teeth in the dentition. In addition, for standardization and comparison, the handpiece was locked into a fixed position. In a clinical practice, the handpiece is usually in motion during treatment and the air polishing spray will not affect a defined area for a supposed treatment time of 5 or $10 \mathrm{~s}$ [25]. However, the effort applied in this investigation may provide the possibility for a careful translation to the clinical situation, i.e. keep the handpiece in motion. An additional clinically relevant finding from our analysis was that an increase in surface alterations occurred for either powder with an increase in treatment time, a decrease in working distance and an angulation of $45^{\circ}$.

\section{Conclusion}

Three air polishing powders designed for the investigated device were compared in terms of their effects on human root 
surfaces. The surface roughness was analysed using the validated and standardized parameters $\mathrm{Pa}, \mathrm{Pt}$ and Rz. All investigated powders altered the root surface according to these three parameters. However, remarkable and significant differences occurred between the powders. There were less effects detectable after the application of two powders containing glycine compared to a powder containing sodium bicarbonate. Within the limits of this in vitro investigation, reason for a wellbalanced use of air polishing powders is provided. Particularly, the use of sodium bicarbonate in periodontally affected dentitions with exposed root surface requires great caution.

Acknowledgments Parts of this research were conducted by J. Bühler in partial fulfilment of the requirements for an MD degree from the University of Basel, Switzerland. Special thanks to S. Galli and P. Schaffner (Basel) for manufacturing the apparatus and preparing the dentin discs.

Conflict of interest The author Fredy Schmidli declares no conflict of interest. This project is supported in part by an unrestricted grant by Electro Medical Devices (EMS) Nyon, Switzerland, to Julia Bühler, Roland Weiger and Clemens Walter.

\section{References}

1. Renvert S, Persson GR (2004) Supportive periodontal therapy. Periodontology 2000 36:179-195

2. Lang NP, Tonetti MS (2003) Periodontal risk assessment (PRA) for patients in supportive periodontal therapy (SPT). Oral Health Prev Dent 1:7-16

3. Axelsson P, Nyström B, Lindhe J (2004) The long-term effect of a plaque control program on tooth mortality, caries and periodontal disease in adults. Results after 30 years of maintenance. J Clin Periodontol 31:749-757

4. Walter C, Weiger R, Zitzmann NU (2011) Periodontal surgery in furcation-involved maxillary molars revisited - an introduction of guidelines for comprehensive treatment. Clin Oral Invest 15:9-20

5. Meyer-Bäumer A, Pritsch M, Cosgarea R, El Sayed N, Kim TS, Eickholz P, Pretzl B (2012) Prognostic value of the periodontal risk assessment in patients with aggressive periodontitis. J Clin Periodontol 39:651-658

6. Lopez NJ, Quintero A, Casanova PA, Martinez B (2013) Threemonthly routine prophylaxes improves chronic periodontitis status in type 2 diabetes. J Periodontol. doi:10.1902/jop.2013.130400

7. Copulos TA, Low SB, Walker CB, Trebilcock YY, Hefti AF (1993) Comparative analysis between a modified ultrasonic tip and hand instruments on clinical parameters of periodontal disease. J Periodontol 64:694-700

8. Schwarz F, Jepsen S, Herten M, Aoki A, Sculean A, Becker J (2007) Immunohistochemical characterization of periodontal wound healing following nonsurgical treatment with fluorescence controlled Er: YAG laser radiation in dogs. Lasers Surg Med 39:428-440

9. Claffey N, Egelberg J (1995) Clinical indicators of probing attachment loss following initial periodontal treatment in advanced periodontitis patients. J Clin Periodontol 22:690-696

10. von Troil B, Needleman I, Sanz M (2002) A systematic review of the prevalence of root sensitivity following periodontal therapy. J Clin Periodontol 29(Suppl 3):173-177, discussion 195-176
11. Draenert ME, Jakob M, Kunzelmann KH, Hickel R (2013) The prevalence of tooth hypersensitivity following periodontal therapy with special reference to root scaling. A systematic review of the literature. Am J Dent 26:21-27

12. Ritz L, Hefti AF, Rateitschak KH (1991) An in vitro investigation on the loss of root substance in scaling with various instruments. J Clin Periodontol 18:643-647

13. Cadosch J, Zimmermann U, Ruppert M, Guindy J, Case D, Zappa U (2003) Root surface debridement and endotoxin removal. J Periodontal Res 38:229-236

14. Petersilka GJ, Bell M, Mehl A, Hickel R, Flemmig TF (2003) Root defects following air polishing. J Clin Periodontol 30:165-170

15. Pelka M, Trautmann S, Petschelt A, Lohbauer U (2010) Influence of air-polishing devices and abrasives on root dentin - an in vitro confocal laser scanning microscope study. Quintessence Int 41:e141e148

16. Slot DE, Koster TJ, Paraskevas S, Van der Weijden GA (2008) The effect of the vector scaler system on human teeth: a systematic review. Int J Dent Hyg 6:154-165

17. Ratka-Krüger P, Mahl D, Deimling D, Monting JS, Jachmann I, AlMachot E, Sculean A, Berakdar M, Jervøe-Storm PM, Braun A (2012) Er:YAG laser treatment in supportive periodontal therapy. J Clin Periodontol 39:483-489

18. Sculean A, Bastendorf KD, Becker C, Bush B, Einwag J, Lanoway C, Platzer U, Schmage P, Schoeneich B, Walter C, Wennström JL, Flemmig TF (2013) A paradigm shift in mechanical biofilm management? Subgingival air polishing: a new way to improve mechanical biofilm management in the dental practice. Quintessence Int 44: 475-477

19. Petersilka GJ, Steinmann D, Häberlein I, Heinecke A, Flemmig TF (2003) Subgingival plaque removal in buccal and lingual sites using a novel low abrasive air-polishing powder. J Clin Periodontol 30:328 333

20. Tada K, Kakuta K, Ogura H, Sato S (2010) Effect of particle diameter on air polishing of dentin surfaces. Odontology 98:31-36

21. Tada K, Wiroj S, Inatomi M, Sato S (2012) The characterization of dentin defects produced by air polishing. Odontology 100:41-46

22. Petersilka GJ, Bell M, Haeberlein I, Mehl A, Hickel R, Flemmig TF (2003) In vitro evaluation of novel low abrasive air polishing powders. J Clin Periodontol 30:9-13

23. Moëne R, Decaillet F, Andersen E, Mombelli A (2010) Subgingival plaque removal using a new air-polishing device. J Periodontol 81: 79-88

24. Wennström JL, Dahlen G, Ramberg P (2011) Subgingival debridement of periodontal pockets by air polishing in comparison with ultrasonic instrumentation during maintenance therapy. J Clin Periodontol 38:820-827

25. Flemmig TF, Hetzel M, Topoll H, Gerss J, Haeberlein I, Petersilka G (2007) Subgingival debridement efficacy of glycine powder air polishing. J Periodontol 78:1002-1010

26. Schlageter L, Rateitschak-Plüss EM, Schwarz JP (1996) Root surface smoothness or roughness following open debridement. An in vivo study. J Clin Periodontol 23:460-464

27. Volk R (2013) Rauheitsmessung: Theorie und praxis. Beuth Verlag $\mathrm{GmbH}$, Berlin

28. Petersilka GJ, Schenck U, Flemmig TF (2002) Powder emission rates of four air polishing devices. J Clin Periodontol 29:694-698

29. Yandell BS (1997) Practical data analysis for designed experiments. Taylor \& Francis Group LLC, Boca Raton

30. R Core Team (2012) R: A language and environment for statistical computing. $\mathrm{R}$ version 2.15.3. R Foundation for Statistical Computing. http://www.R-project.org/. Accessed 1st March 2013

31. Chun K, Choi H, Lee J (2014) Comparison of mechanical property and role between enamel and dentin in the human teeth. J Dent Biomech 5:1758736014520809 
32. Petersilka G, Faggion CM Jr, Stratmann U, Gerss J, Ehmke B, Häberlein I, Flemmig TF (2008) Effect of glycine powder airpolishing on the gingiva. J Clin Periodontol 35:324-332

33. Van der Weijden GA, Timmerman MF (2002) A systematic review on the clinical efficacy of subgingival debridement in the treatment of chronic periodontitis. J Clin Periodontol 29(Suppl 3):55-71

34. Listgarten MA, Ellegaard B (1973) Electron microscopic evidence of a cellular attachment between junctional epithelium and dental calculus. J Periodontal Res 8:143-150

35. Walter C, Buset S, Thillainathan L, Weiger R, Zitzmann NU (2013) Evaluation of periodontal therapy in undergraduate courses of the University of Basel. Schweiz Monatsschr Zahnmed 123:861-869

36. Schaffer EM (1956) Histological results of root curettage of human teeth. J Periodontol 27:296-300

37. Badersten A, Nilveus R, Egelberg J (1981) Effect of nonsurgical periodontal therapy. I. Moderately advanced periodontitis. J Clin Periodontol 8:57-72

38. Kocher T, Rosin M, Langenbeck N, Bernhardt O (2001) Subgingival polishing with a Teflon-coated sonic scaler insert in comparison to conventional instruments as assessed on extracted teeth (II). Subgingival roughness. J Clin Periodontol 28:723-729

39. Vastardis S, Yukna RA, Rice DA, Mercante D (2005) Root surface removal and resultant surface texture with diamondcoated ultrasonic inserts: an in vitro and SEM study. J Clin Periodontol 32:467-473
40. Walmsley AD, Lea SC, Landini G, Moses AJ (2008) Advances in power driven pocket/root instrumentation. J Clin Periodontol 35:22-28

41. Wolf HF, Rateitschak KH, Rateitschak EM (2012) Farbatlanten der Zahnmedizin 1. Parodontologie, Stuttgart, p 544

42. Yassen GH, Platt JA, Hara AT (2011) Bovine teeth as substitute for human teeth in dental research: a review of literature. J Oral Sci 53: 273-282

43. Bester SP, de Wet FA, Nel JC, Driessen CH (1995) The effect of airborne particle abrasion on the dentin smear layer and dentin: an in vitro investigation. Int $\mathrm{J}$ Prosthodont 8:46-50

44. Goodis HE, Marshall GW, White JM (1991) The effects of storage after extraction of the teeth on human dentine permeability in vitro. Arch Oral Biol 36:561-566

45. Strawn SE, White JM, Marshall GW, Gee L, Goodis HE, Marshall SJ (1996) Spectroscopic changes in human dentine exposed to various storage solutions - short term. J Dent 24:417-423

46. Francescut P, Zimmerli B, Lussi A (2006) Influence of different storage methods on laser fluorescence values: a two-year study. Caries Res 40:181-185

47. Bühler J, Schmidli F, Weiger R, Walter C (2012) In vitro analysis of the effects of novel air polishing devices on human teeth-preliminary results. J Clin Periodontol 39(Suppl 13):75

48. Sahrmann P, Ronay V, Schmidlin PR, Attin T, Paqué F (2014) 3-D defect evaluation of air polishing on extracted human roots. J Periodontol 85:1107-1114 